\title{
Early implant removal
}

I read the letter on 'Early implant removal: an ethical dilemma' by Bari et al. ${ }^{1}$ in the January 2013 issue of the Journal with interest, a great feeling of disappointment and I shared the feelings of alarm with the authors. The piece reported a 29-year-old woman who was so dissatisfied with her subdermal implant that she attempted removal herself without anaesthetic and she broke the device. She had requested removal from "several sexual health clinics" but had been turned away.

Refusing removal in this way will surely destroy the reputation of this method and do great harm to the population of contraceptive seekers, as well as the distressed user.

Some years back I worked in Indonesia (and several South Asian countries) where women were often refused early cessation of a contraceptive method. Consequently, in Indonesia especially, Norplant ${ }^{\circledR}$ developed a reputation for causing a high level of unwanted bleeding and other undesirable side effects and uptake fell. Surely we must not make the same mistake again here in Britain?

Jane M Wilson, MSC, DFSRH

GP Partner, Petersfield Medical Practice, Cambridge, UK; wilson.howarth@virgin.net

Competing interests None, although the author does fit subdermal implants and intrauterine devices in general practice in England.

Provenance and peer review Not

commissioned; internally peer reviewed.

J Fam Plann Reprod Health Care 2013;39:233.

doi:10.1136/fprhc-2013-100634

\section{REFERENCE}

1 Bari S, Kulkarni U, Robinson G. Early

implant removal: an ethical dilemma. J Fam

Plann Reprod Health Care 2013;39:64. 